\title{
Metamaterial Based Ultra-Wideband Antennas for Portable Wireless Applications
}

\author{
Mohammad Alibakhshikenari, \\ Mohammad Naser-Moghadasi, \\ Ramazan Ali Sadeghzadeh, Bal Singh Virdee and \\ Ernesto Limiti
}

Additional information is available at the end of the chapter

http://dx.doi.org/10.5772/66674

\begin{abstract}
Antennas are essential for wireless communication systems. The size of a conventional antenna is dictated mainly by its operating frequency. With the advent of ultra-wideband systems (UWB), the size of antennas has become a critical issue in the design of portable wireless devices. Consequently, research and development of suitably small and highly compact antennas are challenging and have become an area of great interest among researchers and radio frequency (RF) design engineers. Various approaches have been reported to reduce the physical size of RF antennas including using high permittivity substrates, shorting pins, reactive components, and more recently, metamaterials (MTM) based on composite right-/left-handed transmission-lines (CRLH-TLs). MTM exhibit unique electromagnetic response that cannot be found in the nature. In this chapter, the properties of CRLH-TL are used to synthesize novel and highly compact planar UWB antennas with radiation properties suitable for wireless mobile devices and systems.
\end{abstract}

Keywords: antennas, ultra-wideband, metamaterials, composite right-/left-hand transmission-lines, microstrip

\section{Introduction}

Electronic circuitry in portable wireless devices is incorporated inside a small and highly integrated transceiver unit [1-4]. Miniaturization of such a system is precluded by the size of the antenna as its dimensions are related to the operating frequency. The most challenging aspect in the development of such systems is the design of miniature antennas [5-8]. In this 
chapter, this issue is addressed by using metamaterial technology. Several different antenna configurations are presented based on CRLH-TL/MTM unit cells [9-22].

In part 2, antenna designs are described based on simplified CRLH-TLs that are implemented using F-shaped and T-shaped dielectric slits embedded on the antenna's groundplane and radiating arms, respectively. This antenna is shown to operate across $0.65-9.2 \mathrm{GHz}$ with a maximum gain and radiation efficiency of $3.5 \mathrm{dBi}$, and $70 \%$ at $4.5 \mathrm{GHz}$, respectively. This antenna has dimensions of $25 \times 15 \times 1.6 \mathrm{~mm}^{3}$. In another example, how size reduction and bandwidth extension can be achieved using CRLH-TL unit cells that are composed of a U-shaped slit and grounded spiral microstrip stub are shown.

In part 3, the antenna is implemented by cascading together in series several identical MTM unit cells. The unit cell is composed of a transmission line that has engraved on its patch a mirror image of E-shaped slits and high impedance spiral stub that is grounded through a metal via-hole. Two antennas implemented using this technique have dimensions of $0.017 \lambda_{0} \times 0.006 \lambda_{0} \times 0.001 \lambda_{0}$ and $0.028 \lambda_{0} \times 0.008 \lambda_{0} \times 0.001 \lambda_{0^{\prime}}$ where $\lambda_{0}$ is free space wavelength at 500 and $650 \mathrm{MHz}$, respectively. The respective antennas have bandwidths of $850 \mathrm{MHz}(0.5-1.35 \mathrm{GHz})$ and $1.2 \mathrm{GHz}$ $(0.65-1.85 \mathrm{GHz})$, which correspond to fractional bandwidths of $91.9 \%$ and $96.0 \%$, respectively. Besides the small dimensions and wide bandwidth characteristics, the measured gain and efficiency of one antenna at $1 \mathrm{GHz}$ are $5.3 \mathrm{dBi}$ and $85 \%$, respectively; and the second antenna has a gain and efficiency of $5.7 \mathrm{dBi}$ and $90 \%$, respectively, at $1.4 \mathrm{GHz}$.

In part 4, antenna size reduction and bandwidth extension is realized with MTM unit cells that are composed of U-shaped dielectric slit and spiral conductor that is grounded using via-holes. The design of the antenna presented here functions over the frequency range of $5.8-7.3 \mathrm{GHz}$, i.e. it has a fractional bandwidth of $23 \%$. The antenna's performance was measured to verify it has a wide bandwidth, high gain, and high radiation efficiency properties. At $6.6 \mathrm{GHz}$, the antenna is shown to exhibit a radiation gain of $4.8 \mathrm{dBi}$, fractional bandwidth of $23 \%$, and efficiency of $78 \%$. Furthermore, the proposed antenna is very compact and has dimensions of $0.39 \lambda_{0} \times 0.13 \lambda_{0} \times 0.015 \lambda_{0}$.

In part 5, the MTM unit-cell is composed of T-shaped dielectric slit that is etched on the radiating patch and includes a grounded conductive spiral stub. The T-shaped slit antenna is shown to operate over 1.1-6.85 GHz (fractional bandwidth $~ 145 \%$ ) with a maximum gain and efficiency of $7.1 \mathrm{dBi}$ and $91 \%$, respectively, at $3.7 \mathrm{GHz}$. This antenna has an electrical size of $0.05 \lambda_{0} \times 0.02 \lambda_{0} \times 0.002 \lambda_{0}$.

The aforementioned MTM antennas exhibit superior performance compared to conventional antennas in terms of fractional bandwidth, gain, and efficiency. These antennas are suitable for UWB wireless communication systems, portable microwave handsets, and transceivers.

\section{UWB antenna based on simplified CRLH-TL}

The simplified composite right-/left-handed transmission-lines (SCRLH-TL) used here in the design are a novel planar antenna. The SCRLH-TL is implemented by loading the radiation patch and ground-plane with dielectric T-shaped and F-shaped slits, respectively, as shown 
in Figure 1. With the assistance of 3D full-wave electromagnetic simulator (HFSS $\left.{ }^{\mathrm{TM}}\right)$, the dimensions of the dielectric slits can be optimized. The design of Antenna\#1 consists of two identical structures that can be considered to be a mirror image, where one of the structures has been flipped sideways, as shown in Figure 1(a). The F-shaped dielectric slits embedded in the ground-plane essentially behave like left-handed series capacitance; and the T-shaped dielectric slits embedded in the radiation patch are used to enhance the radiation characteristics of the antenna. To improve the impedance matching of the feed-line to the antenna, it is necessary to load the feed-line with an H-shaped microstrip stub, as shown in Figure 1. The two SMA connectors on the opposite sides of antenna are used to excite the antenna through the conductor-backed coplanar waveguide (CPW) transmission-lines.

The gain and radiation efficiency of any antenna can be improved by simply increasing the aperture of the antenna. To increase the magnitude of these two characterizing parameters, the number of patches in the proposed design was increased from two to four, as shown in Figure 1(b). The advantage of the technique presented here in comparison to conventional methods is that it does not affect the physical size of the antenna as the additional patches are contained within the antenna structure. To enhance the antenna's impedance bandwidth, the number of F-shaped slits in the ground-plane was halved from four to two, thus effectively reducing the left-handed series capacitance.

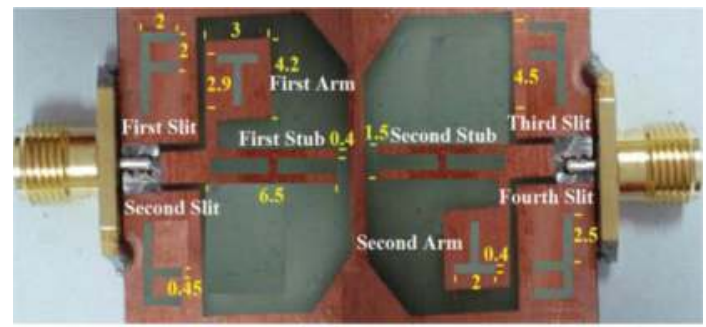

(a)

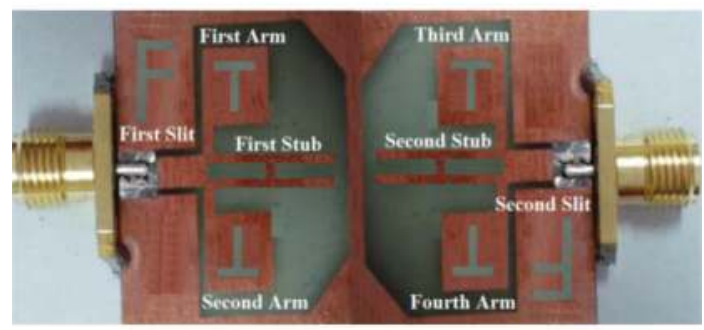

(b)

Figure 1. Antenna configurations, (a) Antenna\#1 and (b) Antenna\#2. Design parameters of both antennas are identical. Dimensions (in $\mathrm{mm}$ ) are annotated.

The antennas were fabricated on $\mathrm{RD} /$ duroid $^{\circledR} \mathrm{RO} 4003$ substrate with dielectric constant of 3.38 , thickness of $1.6 \mathrm{~mm}$, and tan $\delta$ of $22 \times 10^{-4}$. The dimensions of the two antennas are: $25 \times 15 \times 1.6 \mathrm{~mm}^{3}$ which is equivalent to an electrical size of $0.054 \lambda_{0} \times 0.032 \lambda_{0} \times 0.003 \lambda_{0^{\prime}}$, where $\lambda_{0}$ corresponds to 
$0.65 \mathrm{GHz}$. The antenna's reflection-coefficient response (simulated and measured) is shown in Figure 2. The antenna's frequency of operation and bandwidth is given in Table 1. Antenna\#1 has a measured bandwidth of $7.4 \mathrm{GHz}$ and Antenna\#2 has a bandwidth of $8.55 \mathrm{GHz}$. The fractional bandwidth of Antenna\#2 is $16 \%$ greater than Antenna\#1. Figure 3 shows the measured antenna gain and efficiency response of both antennas. The antenna gain and efficiency values at spot frequencies are also tabulated in Table 2. Results show that Antenna\#2 has a maximum gain and radiation efficiency of $3.5 \mathrm{dBi}$ and $70 \%$ at $4.5 \mathrm{GHz}$, which is higher than Antenna\# 1 by $25 \%$ and $27 \%$, respectively.

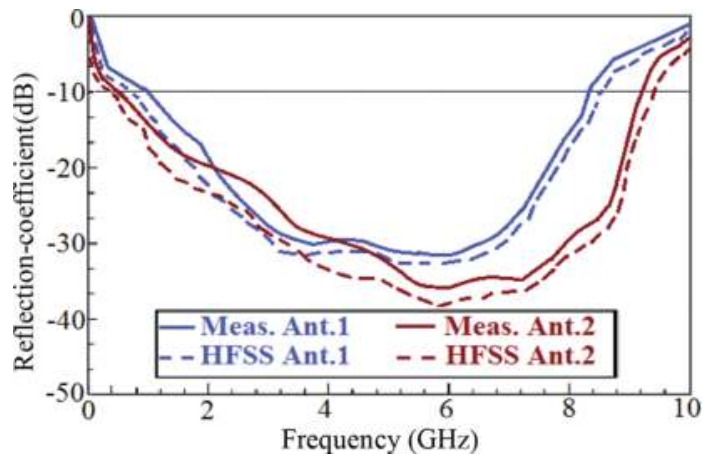

Figure 2. Simulated and measured reflection-coefficient response of the two antennas.

\begin{tabular}{lll}
\hline & Operating frequency range (fractional bandwidth) \\
\hline & Simulated & Measured \\
Antenna\#1 & $0.82-8.6 \mathrm{GHz}(165.2 \%)$ & $1-8.4 \mathrm{GHz}(157.4 \%)$ \\
Antenna\#2 & $0.5-9.45 \mathrm{GHz}(179.9 \%)$ & $0.65-9.2 \mathrm{GHz}(173.6 \%)$ \\
\hline
\end{tabular}

Table 1. Operating frequency range and impedance bandwidth of the proposed antennas.

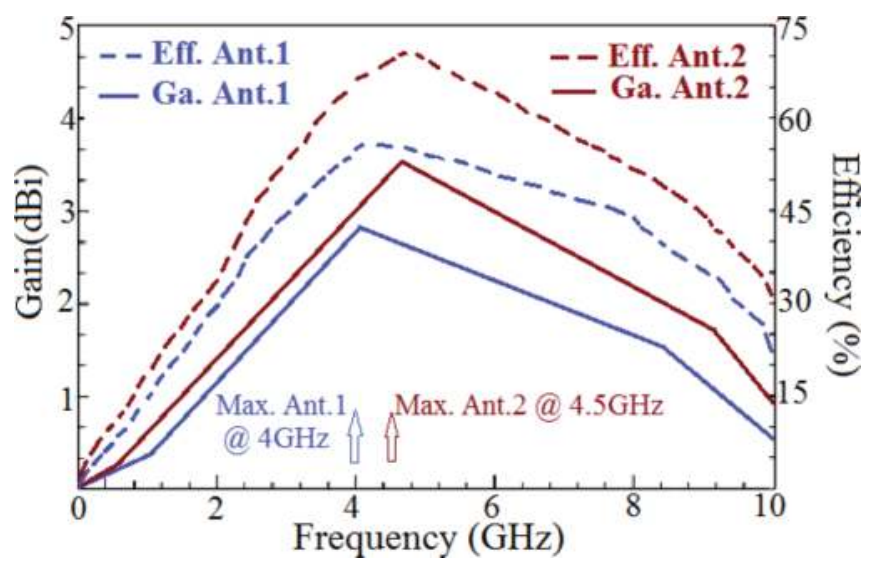

Figure 3. Measured gain and efficiency response of both antennas. 


\begin{tabular}{lll}
\hline Antennas & Gain (dBi) & Efficiency (\%) \\
\hline Ant.\#1 @ 1, 4, and 8.4 GHz & $0.4,2.8$, and 1.5 & 15,55, and 40 \\
Ant.\#2 @ 0.65, 4.5, and 9.2 GHz & $0.2,3.5$, and 1.7 & 12,70 , and 42 \\
\hline
\end{tabular}

Table 2. Gain and radiation characteristics of the two antennas.

Radiation characteristics (copolarization and crosspolarization) of the two antennas in the E-plane and H-plane at $2.5 \mathrm{GHz}, 4 \mathrm{GHz}$, and $4.5 \mathrm{GHz}$ are shown in Figure 4 . The results show both antennas radiate omnidirectionally in the E-plane and bidirectionally in the H-plane. The low profile UWB antennas facilitate easy integration in wireless systems and can be flush mounted on various structures.
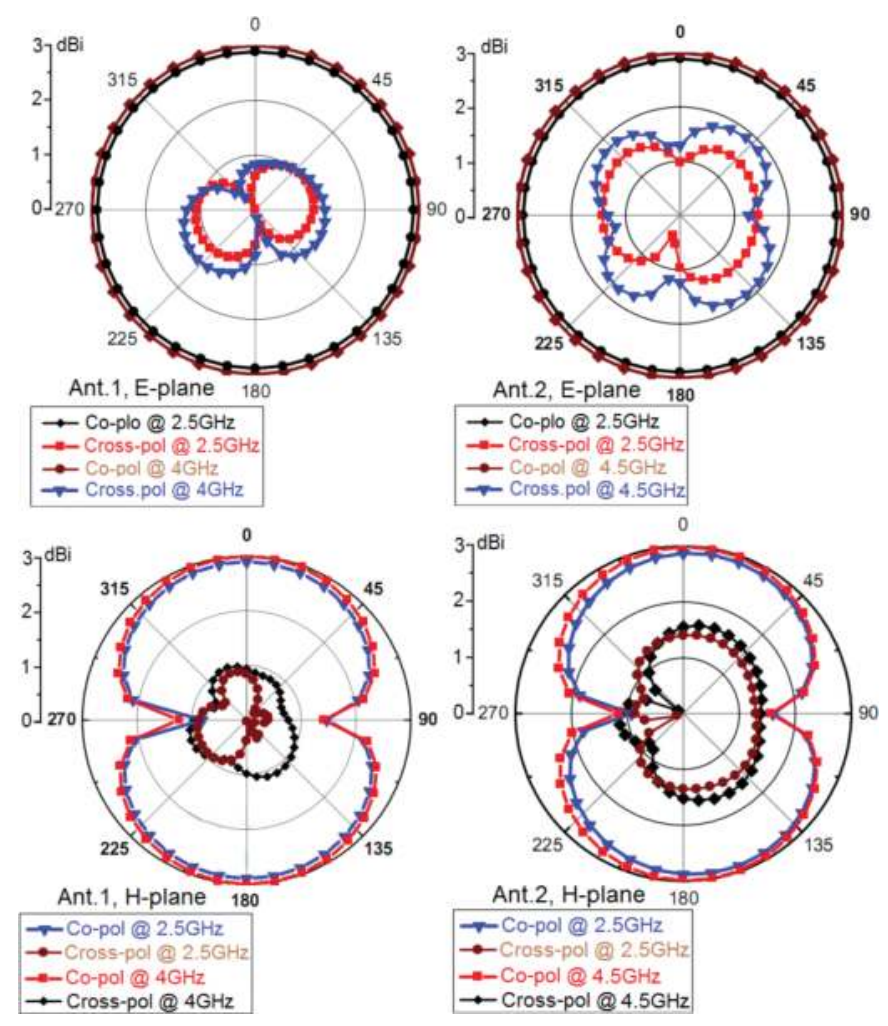

Figure 4. Measured radiation patterns at 2.5, 4, and 4.5 GHz.

\section{Wideband antenna using E-shaped slit MTM unit cells}

The goal in this section is to design antennas that can fit within an area of $15 \times 5 \mathrm{~mm}^{2}$ for flush mounting on various structures including vehicles and portable wireless devices, and possess 
characteristics of wide operational bandwidth with good radiation properties. The unique antenna design is based on MTM unit cell, shown in Figure 5, and comprises a microstrip patch on which is etched mirror image of E-shaped dielectric slits and the unit cell is grounded using a conductive spiral stub. The E-shaped slits and spiral stub act as left-handed (LH) capacitance $\left(C_{L}\right)$ and shunt inductance $\left(L_{L}\right)$, respectively, corresponding to the negative permeability $(\mu<0)$ and the negative permittivity $(\varepsilon<0)$, respectively, and are represented by [23-26]:

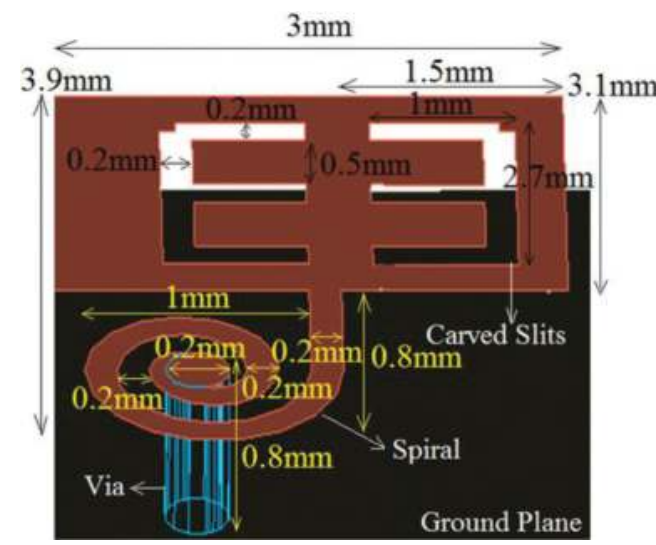

Figure 5. MTM unit cell geometry.

$$
\begin{aligned}
\jmath & =\frac{Z}{j \omega}=\frac{1}{\omega^{2} C_{L}}{ }^{`}+L_{R}(Z \text { : series impedence }) \\
\varepsilon & =\frac{Y}{j \omega}=\frac{1}{\omega^{2} L_{L}}+C_{R}(Y \text { : shunt admittance })
\end{aligned}
$$

Surface current flow on the patch constituting the unit cell introduces right-handed $(\mathrm{RH})$ series inductance $\left(L_{R}\right)$, and the gap between patch and the ground plane introduces shunt $\mathrm{RH}$ capacitance $\left(C_{R}\right)$, which are related to positive permeability $(\mu>0)$ and positive permittivity $(\varepsilon>0)$, respectively, defined by Eqs. (3) and (4). The loss in the unit cell structure can be modeled by series RH resistance $\left(R_{R}\right)$, shunt LH resistance $\left(R_{L}\right)$, shunt RH conductance $\left(G_{R}\right)$, and series LH conductance $\left(G_{L}\right)$. The equivalent circuit model of the unit cell is shown in Figure 6 .

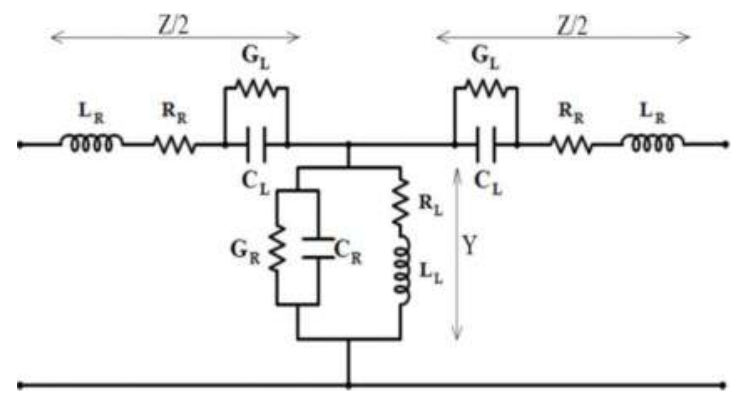

Figure 6. Equivalent circuit model of the MTM unit cell.

The values for the electrical parameters $C_{L^{\prime}} L_{L^{\prime}} C_{R^{\prime}} L_{R^{\prime}} R_{R^{\prime}} R_{L^{\prime}} G_{R^{\prime}}$ and $G_{L}$ are $4.2 \mathrm{pF}, 5.4 \mathrm{nH}$, $2.1 \mathrm{pF}, 2.9 \mathrm{nH}, 1.2 \Omega, 1.85 \Omega, 0.85 \Omega$, and $1.15 \Omega$, respectively. 


$$
\begin{aligned}
& \mu=\frac{Z}{j \omega}=L_{R}-\frac{1}{\omega^{2} C_{L}} \\
& \varepsilon=\frac{Y}{j \omega}=C_{R}-\frac{1}{\omega^{2} L_{L}}
\end{aligned}
$$

Restriction in the antenna size required its characteristics to be optimized by full wave simulators, i.e., Keysight Technologies Advanced Design System (ADS) and Ansys High Frequency Structure Simulator (HFSS ${ }^{\mathrm{TM}}$ ). The antenna's characteristics were tuned by modifying the dimensions of the E-shaped slit, the gap between slits, the dimensions of the spiral, and the number of spiral turns. The optimized MTM unit cell is shown in Figure 5. The two antenna designs use two and three MTM unit cells, respectively, that are cascaded together in series. The antennas are constructed using standard manufacturing techniques on FR4 substrate with dielectric constant of 4.6, thickness of $0.8 \mathrm{~mm}$, and tan $\delta$ of 0.01 . The prototype antenna designs are shown in Figure 7. Port 1 is used to excite both antennas, and port 2 is matched to $50 \Omega$ load impedance (SMD1206).

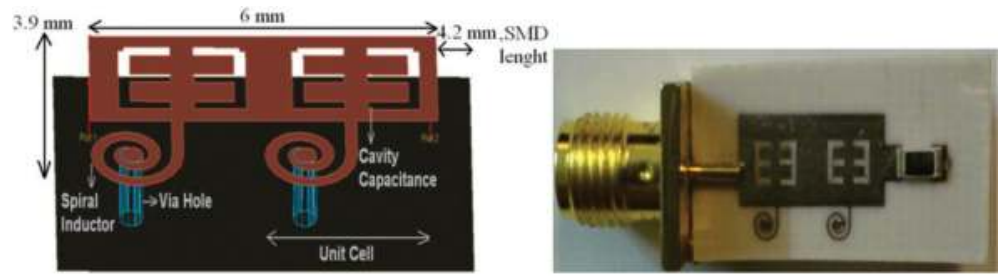

Antenna $\# 3$ using two MTM unit cells

Fabricated prototype of Antenna $\# 3$

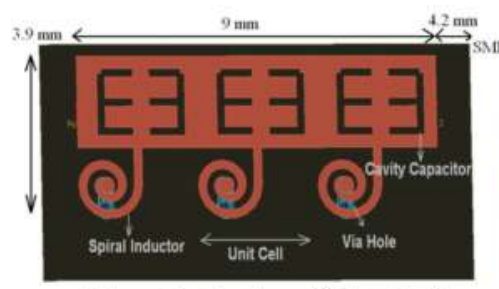

Antenna $\$ 4$ using three MTM unit cells

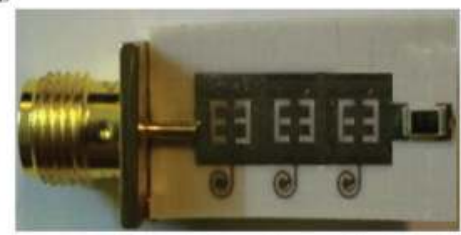

Fabricated prototype of Antenna $\# 4$

Figure 7. Fabricated MTM antennas.

The physical size of the Antenna\#3 (two unit cell) is $10.2 \times 3.9 \times 0.8 \mathrm{~mm}^{3}\left(0.017 \lambda_{0} \times 0.006 \lambda_{0} \times\right.$ $0.001 \lambda_{0^{\prime}}$ where $\lambda_{0}$ is the free space wavelength at $\left.500 \mathrm{MHz}\right)$; and the size of the Antenna\#4 (three unit cell) is $13.2 \times 3.9 \times 0.8 \mathrm{~mm}^{3}\left(0.028 \lambda_{0} \times 0.008 \lambda_{0} \times 0.001 \lambda_{0^{\prime}}\right.$ where $\lambda_{0}$ is the free space wavelength at $650 \mathrm{MHz}$. The simulated and measured bandwidth of both antennas is given in Table 3, and its reflection coefficient response is shown in Figures $\mathbf{8}$ and $\mathbf{9}$.

The simulated and measured gain and efficiency response of the Antenna\#3 and Antenna\#4 are shown in Figures $\mathbf{1 0}$ and 11, as well as tabulated in Tables 4 and 5. The results show the three unit cell antenna offers better gain and efficiency than the two unit cell; however, this is at the cost of slightly larger antenna size. The radiation pattern of both antennas in the Eand H-planes at various spot frequencies is shown in Figure 12. Both antennas radiate power omnidirectionally; however, Antenna 4 radiates bidirectionally at $1.85 \mathrm{GHz}$. The radiation properties were measured using a network analyzer in a standard microwave anechoic chamber. Properties of the two antennas are compared with other planar MTM antennas in Table 6. 
Table 6 shows that Antennas\#3 and \#4 are smaller in size and have a high gain and efficiency than other reported antennas.

\begin{tabular}{lll}
\hline & Antenna\#3 & Antenna\#4 \\
\hline ADS & $1.4 \mathrm{GHz}(200 \mathrm{MHz}-1.60 \mathrm{GHz})$ & $1.6 \mathrm{GHz}(400 \mathrm{MHz}-2 \mathrm{GHz})$ \\
HFSS $^{\mathrm{TM}}$ & $1.2 \mathrm{GHz}(350 \mathrm{MHz}-1.55 \mathrm{GHz})$ & $1.55 \mathrm{GHz}(350 \mathrm{MHz}-1.9 \mathrm{GHz})$ \\
Measured & $0.85 \mathrm{GHz}(500 \mathrm{MHz}-1.35 \mathrm{GHz})$ & $1.2 \mathrm{GHz}(650 \mathrm{MHz}-1.85 \mathrm{GHz})$ \\
\hline
\end{tabular}

Table 3. Simulated and measured impedance bandwidth for Antenna\#3 and \#4.

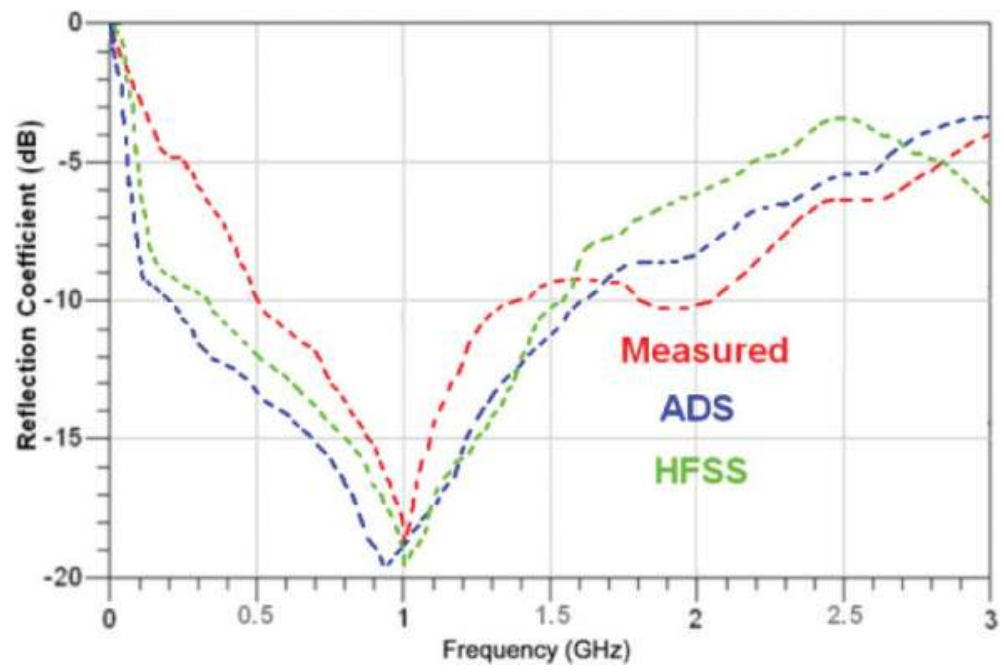

Figure 8. Simulated and measured $S_{11}$ of Antenna $\# 3$.

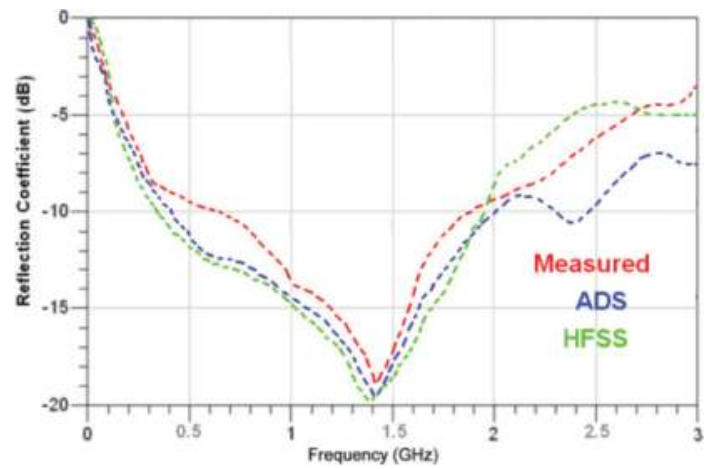

Figure 9. Simulated and measured $\mathrm{S}_{11}$ of Antenna\#4. 


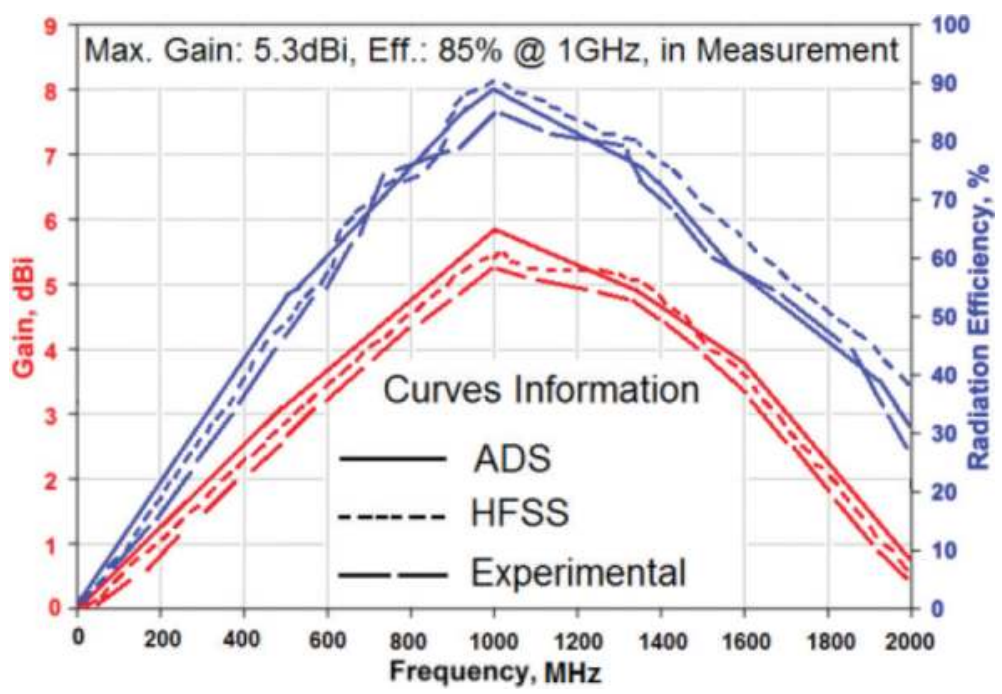

Figure 10. Gain and efficiency of Antenna\#3.

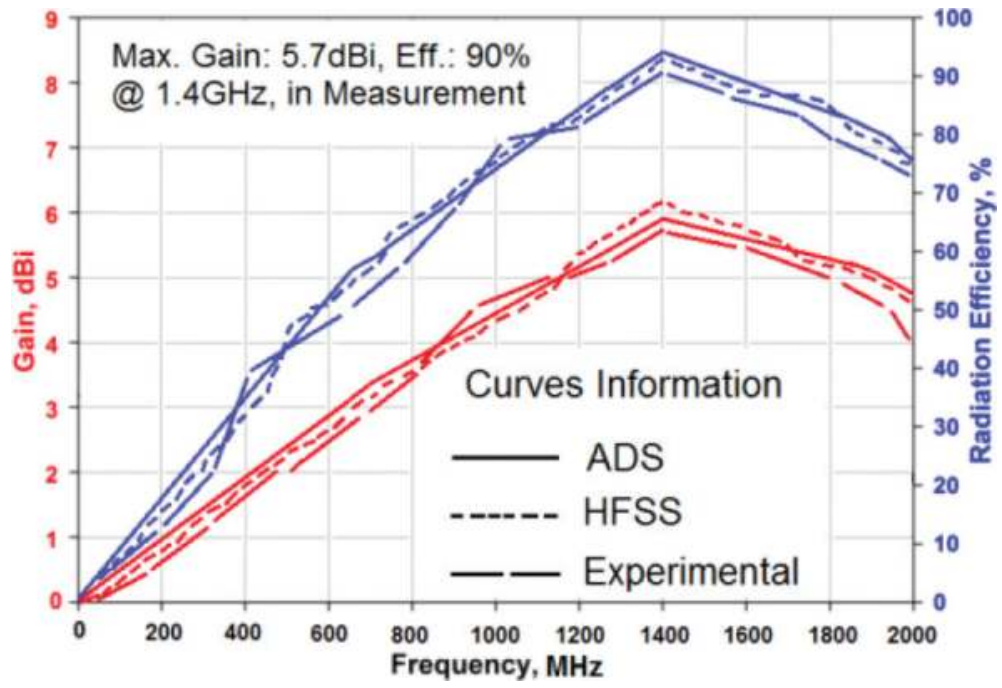

Figure 11. Gain and efficiency of Antenna\#4.

\begin{tabular}{llll}
\hline Freq. (GHz) & $\mathbf{0 . 5}$ & $\mathbf{1}$ & $\mathbf{1 . 3 5}$ \\
\hline ADS & $3.1 \mathrm{dBi} / 53 \%$ & $5.8 \mathrm{dBi} / 88 \%$ & $4.9 \mathrm{dBi} / 75 \%$ \\
HFSS $^{\text {TM }}$ & $2.8 \mathrm{dBi} / 51 \%$ & $5.5 \mathrm{dBi} / 90 \%$ & $5.1 \mathrm{dBi} / 79 \%$ \\
Measured & $2.6 \mathrm{dBi} / 48 \%$ & $5.3 \mathrm{dBi} / 85 \%$ & $4.7 \mathrm{dBi} / 73 \%$ \\
\hline
\end{tabular}

Table 4. Radiation characteristics (gain/efficiency) of Antenna\#3. 


\begin{tabular}{llll}
\hline Freq. (GHz) & $\mathbf{0 . 6 5}$ & $\mathbf{1 . 4}$ & $\mathbf{1 . 8 5}$ \\
\hline ADS & $3.2 \mathrm{dBi} / 57 \%$ & $5.9 \mathrm{dBi} / 94 \%$ & $5.3 \mathrm{dBi} / 81 \%$ \\
HFSS & $3.0 \mathrm{dBi} / 55 \%$ & $6.1 \mathrm{dBi} / 93 \%$ & $5.2 \mathrm{dBi} / 80 \%$ \\
Measured & $2.8 \mathrm{dBi} / 51 \%$ & $5.7 \mathrm{dBi} / 90 \%$ & $4.9 \mathrm{dBi} / 78 \%$ \\
\hline
\end{tabular}

Table 5. Radiation characteristics (gain/efficiency) of Antenna\#3.

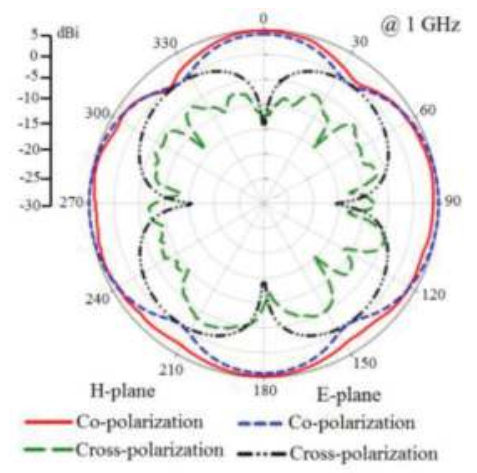

For Antenna $\# 3$

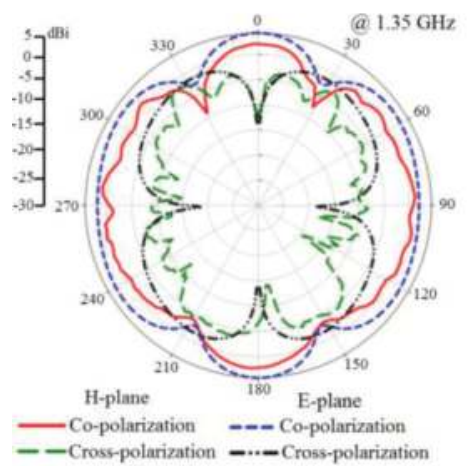

For Antenna $\sharp 3$

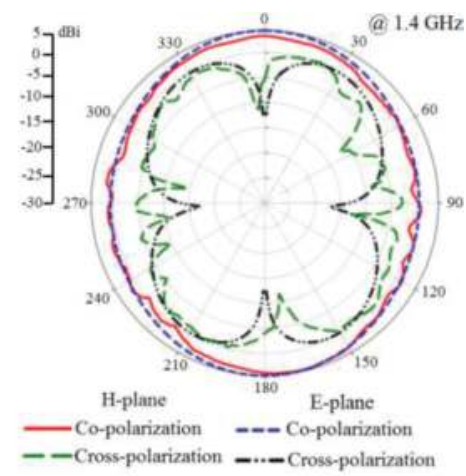

For Antenna $\# 4$

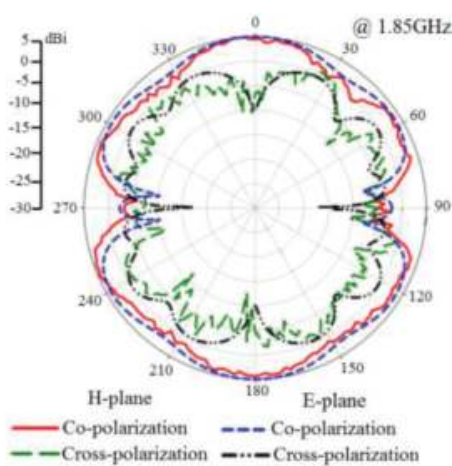

For Antenna $\$ 4$

Figure 12. Measured E- and H-plane co- and cross-polarization radiation patterns.

\begin{tabular}{lllll}
\hline Reference & Dimensions & Bandwidth & Gain (max) & Eff. (max) \\
\hline [27] b-shaped & $E S: 0.047 \lambda_{0} \times 0.021 \lambda_{0} \times$ & $104.76 \%$ & $2.3 \mathrm{dBi}$ & $62 \%$ \\
antenna with $4 \times \mathrm{UC}$ & $\begin{array}{l}0.002 \lambda_{0} \text { at } 1 \mathrm{GHz} \\
\text { PHS: } 14.2 \times 6.32 \times 0.8 \mathrm{~mm}^{3}\end{array}$ & $(1-3.2 \mathrm{GHz})$ & & \\
& $E S: 0.051 \lambda_{0} \times 0.016 \lambda_{0} \times$ & $123.8 \%$ & & \\
[27] b-shaped & $0.002 \lambda_{0}$ at $800 \mathrm{MHz}$ & $(0.8-3.4 \mathrm{GHz})$ & & $70 \%$ \\
antenna with 6 $\times \mathrm{UC}$ & $P H S: 19.2 \times 6.32 \times 0.8 \mathrm{~mm}^{3}$ & & & \\
& $E S: 0.564 \lambda_{0} \times 0.175 \lambda_{0} \times$ & $84.23 \%$ & $2.4 \mathrm{dBi}$ & $48.2 \%$ \\
[28] J-shaped antenna & $(7.25-17.8 \mathrm{GHz})$ & & \\
with 8 $\times$ UC & $0.02 \lambda_{0}$ at $7.5 \mathrm{GHz}$ & &
\end{tabular}




\begin{tabular}{lllll}
\hline Reference & Dimensions & Bandwidth & Gain (max) & Eff. (max) \\
\hline [28] I-shaped antenna & $E S: 0.556 \lambda_{0} \times 0.179 \lambda_{0} \times$ & $87.16 \%$ & $3.4 \mathrm{dBi}$ & $68.1 \%$ \\
with 7 $\times$ UC & $0.041 \lambda_{0}$ at $7.7 \mathrm{GHz}$ & $(7.8-19.85 \mathrm{GHz})$ & & \\
& $P H S: 21.7 \times 7 \times 1.6 \mathrm{~mm}^{3}$ & & & \\
E-shaped slit antenna & $E S: 0.017 \lambda_{0} \times 0.006 \lambda_{0} \times$ & $91.89 \%$ & $5.3 \mathrm{dBi}$ & $85 \%$ \\
with 2 $\times$ UC & $0.001 \lambda_{0}$ at $500 \mathrm{MHz}$ & $(0.5-1.35 \mathrm{GHz})$ & & \\
& $P H S: 10.2 \times 3.9 \times 0.8 \mathrm{~mm}^{3}$ & & & \\
E-shaped slit antenna & $E S: 0.028 \lambda_{0} \times 0.008 \lambda_{0} \times$ & $96 \%$ & $5.7 \mathrm{dBi}$ & \\
with 3 $\times$ UC & $0.001 \lambda_{0}$ at $650 \mathrm{MHz}$ & $(0.65-1.85 \mathrm{GHz})$ & & \\
& $P H S: 13.2 \times 3.9 \times 0.8 \mathrm{~mm}^{3}$ & & & \\
\hline
\end{tabular}

UC, unit cells; ES, electrical size; PHS, physical size.

Table 6. Antenna characteristics.

\section{Wideband antenna using U-shaped slit MTM unit cells}

A novel and compact planar antenna is described that promotes size reduction and bandwidth extension. The antenna is essentially a rectangular patch which is loaded with six MTM unit cells, where each unit cell consists of a U-shaped dielectric slit and a spiral conductor that is grounded using a metallic via-hole, as shown in Figure 13. The antenna is terminated on the right-hand side to a matched load of $20 \Omega$ using SMD1206. The load is terminated to the ground-plane through a via-hole.

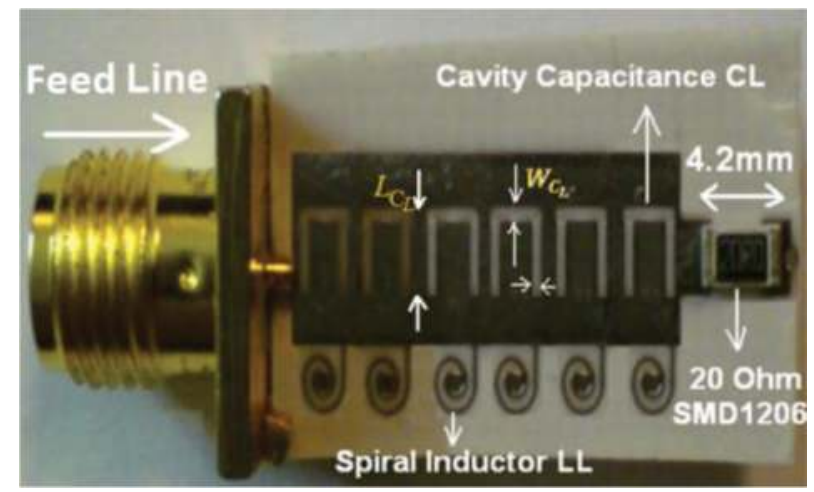

Figure 13. Fabricated prototype MTM antenna.

The U-shaped slit and spiral act like left-handed series capacitance $\left(C_{L}\right)$ and shunt inductance $\left(L_{L}\right)$, respectively. The current flow on the antenna structure and the voltage gradient created between the antenna and the ground-plane induces parasitic right-handed $(\mathrm{RH})$ series inductance $\left(L_{R}\right)$ and shunt capacitance $\left(C_{R}\right)$, respectively. The equivalent circuit model of the MTM unit-cell is shown in Figure 14. In addition to the four reactive components $\left(C_{L^{\prime}} L_{L^{\prime}} L_{R^{\prime}}\right.$ and $\left.C_{R}\right)$, 
right-handed lossy components $R_{R}$ and $G_{R}$ and left-handed lossy components $G_{L}$ and $R_{L}$ are included, which account for the dielectric loss associated with $C_{L}$ and the ohmic loss associated with $L_{L}$. The metamaterial antenna was fabricated on a RT/duroid ${ }^{\mathrm{TM}} \mathrm{RO} 4003$ substrate with dielectric constant of 3.38, thickness of $0.8 \mathrm{~mm}$, and $\tan \delta=0.0022$. The magnitudes of the unit-cell parameters were determined from simulation and these are: $C_{L}=3.2 \mathrm{pF}, L_{L}=4.5 \mathrm{nH}$, $C_{R}=1.5 \mathrm{pF}, L_{R}=3.44 \mathrm{nH}, G_{L}=5.6 \mathrm{~S}, G_{R}=3.2 \mathrm{~S}, R_{L}=6 \Omega$, and $R_{R}=4.2 \Omega$.

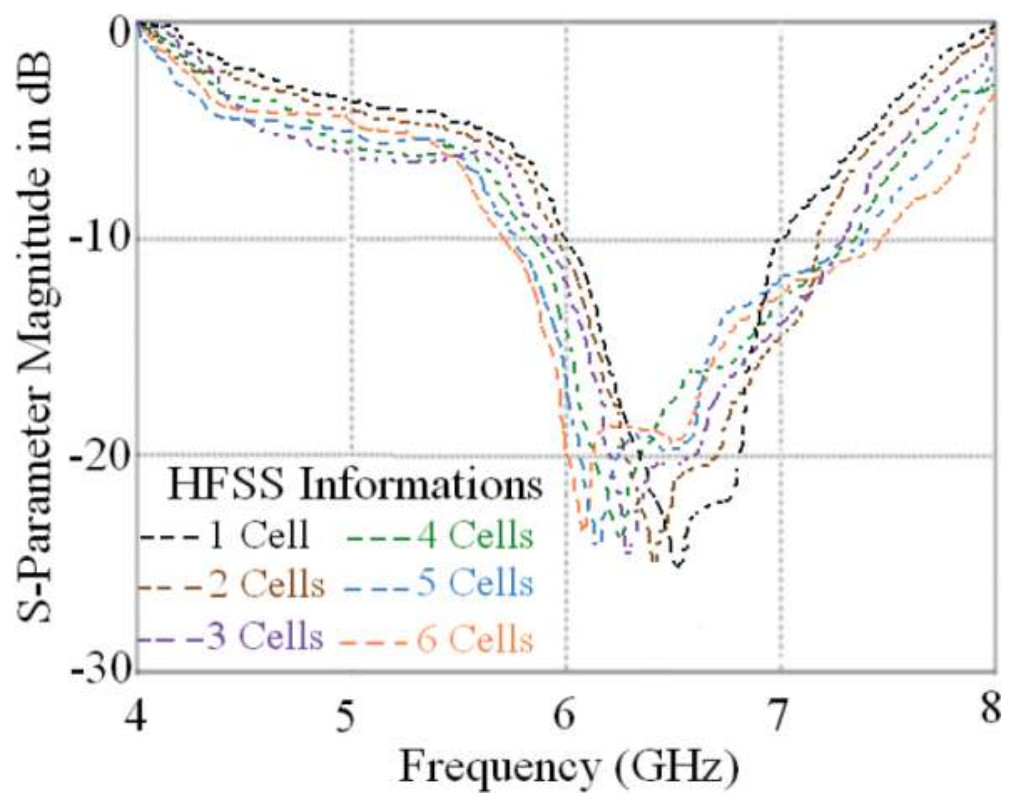

Figure 14. Reflection-coefficient response of the MTM antenna for various number of unit cells.

Trade-off between the antenna size, bandwidth, and radiation properties was used to determine the number of MTM unit cells. In the example presented here, the aim was to design and construct an antenna that had a length of $20 \mathrm{~mm}$ and operated over a wide frequency range with good unidirectional radiation characteristics. It was necessary to use HFSS ${ }^{\mathrm{TM}}$ to optimize the antenna design. The antenna's reflection-coefficient response as a function of number of unit cells is shown in Figure 15. Six unit cells provide the widest impedance bandwidth of $1.75 \mathrm{GHz}$ for a reflection-coefficient of $10 \mathrm{~dB}$. Therefore, six unit cells were used here in the antenna design.

The antenna's reflection-coefficient (simulated and measured) is shown in Figure 16. The impedance bandwidth of the antenna is $29 \%, 26.8 \%$, and $26.6 \%$ using ADS, HFSS ${ }^{\mathrm{TM}}$, and CST MWS, respectively. The measured impedance bandwidth is $1.5 \mathrm{GHz}(5.8-7.3 \mathrm{GHz})$ for IS11। $<-10 \mathrm{~dB}$, which corresponds to $23.7 \%$. There is $13.7 \%$ differential between the averaged simulation and measurement results. 


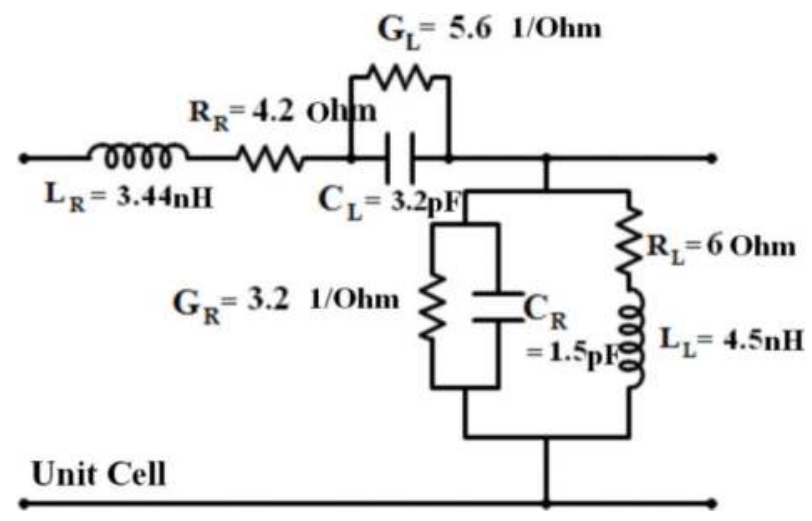

Figure 15. Equivalent circuit model of the MTM unit cell.

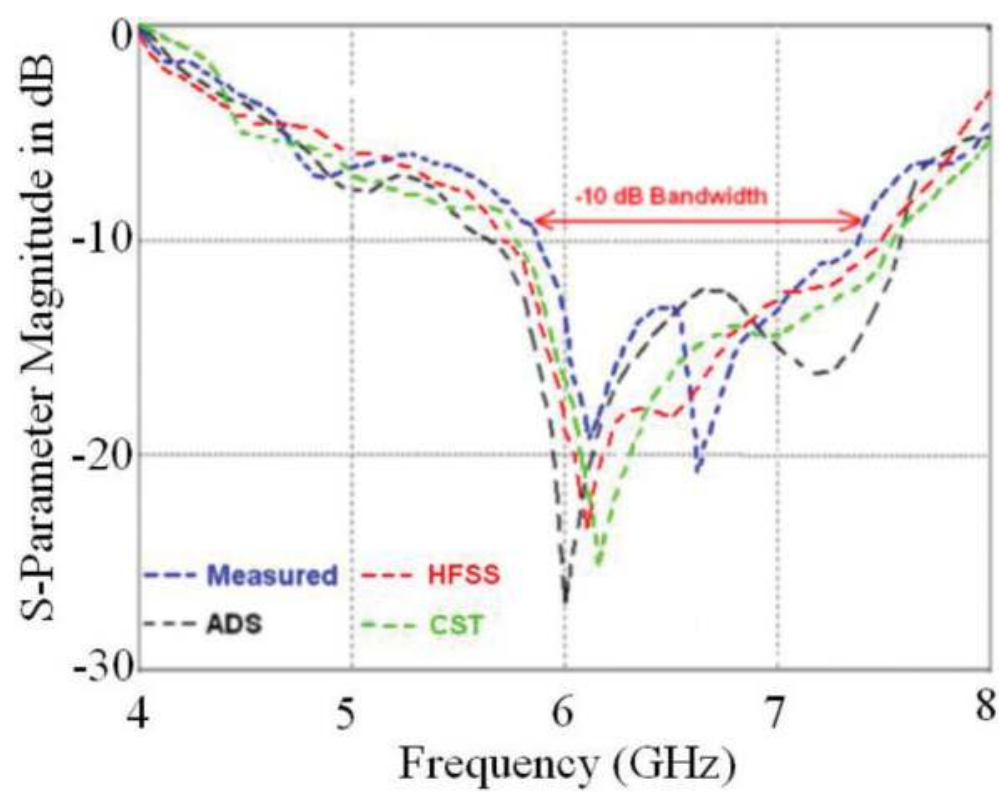

Figure 16. Measured and simulated of $\left|S_{11}\right|$ of the MTM antenna.

Future wireless systems require antennas that possess good radiation characteristics such as gain and efficiency in addition to compact size and wide bandwidth. The effective aperture of the antenna determines its gain and radiation efficiency. The magnitude of these two characterizing parameters can be improved simply by increasing the antenna's effective crosssectional area. However, this traditional technique increases the dimensions of the antenna which is undesirable. Figure $\mathbf{1 7}$ shows the effective aperture of the antenna can be increased 
by loading it with several MTM unit cells without increasing the antenna size. Results show that with four unit cells the gain and efficiency of the antenna at $7 \mathrm{GHz}$ are $4.94 \mathrm{dBi}$ and $74 \%$, respectively. In fact, by increasing in the number of MTM unit cells from four to six improves the gain to $6.1 \mathrm{dBi}$ and the efficiency to $85 \%$. Table 7 provides the parameters of the optimized antenna and its equivalent electrical circuit. The measured E-plane and $\mathrm{H}$-plane radiation pattern at $5.8 \mathrm{GHz}, 6.6 \mathrm{GHz}$, and 7.3 GHz is shown in Figure 18. The antenna radiates unidirectionally with $3 \mathrm{~dB}$ angular beamwidth of 90 degrees.

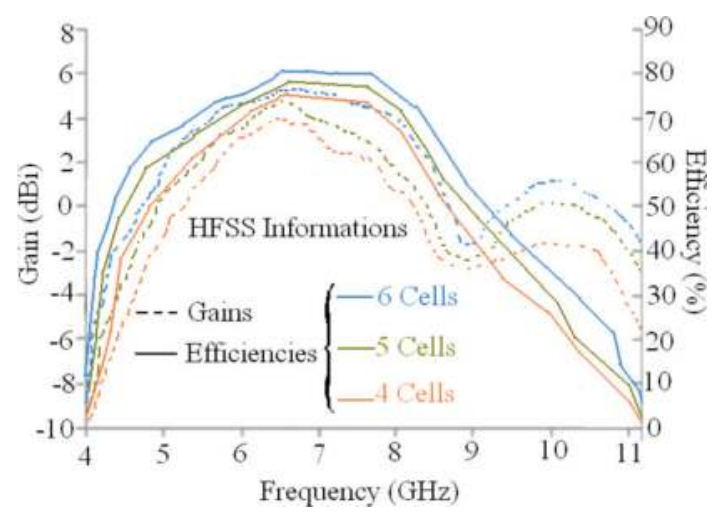

Figure 17. Gain and efficiency performance as a function of number of MTM unit cells.

\begin{tabular}{ll}
\hline Number of unit cells & 6 \\
\hline Length $\left(L_{C_{L}}\right)$ & $2.50 \mathrm{~mm}$ \\
Width $\left(W_{C_{L}}\right)$ & $0.50 \mathrm{~mm}$ \\
Gap between slits & $0.60 \mathrm{~mm}$ \\
Width of spiral & $0.25 \mathrm{~mm}$ \\
Spacing of spirals & $0.25 \mathrm{~mm}$ \\
Spiral turns & 2 \\
Height of via-hole & $0.80 \mathrm{~mm}$ \\
Length of SMD1206 & $4.20 \mathrm{~mm}$ \\
SMD1206 & $20 \Omega$ \\
$C_{L}$ & $3.2 \mathrm{pF}$ \\
$L_{L}$ & $4.5 \mathrm{nH}$ \\
$C_{R}$ & $1.5 \mathrm{pF}$ \\
$L_{R}$ & $3.4 \mathrm{nH}$ \\
$G_{L}$ & $5.6 \mathrm{~S}$
\end{tabular}




\begin{tabular}{ll}
\hline Number of unit cells & 6 \\
\hline$G_{R}$ & $3.2 \mathrm{~S}$ \\
$R_{L}$ & $6.0 \Omega$ \\
$R_{R}$ & $4.2 \Omega$ \\
\hline
\end{tabular}

Table 7. Dimensions of the MTM antenna and parameter values.

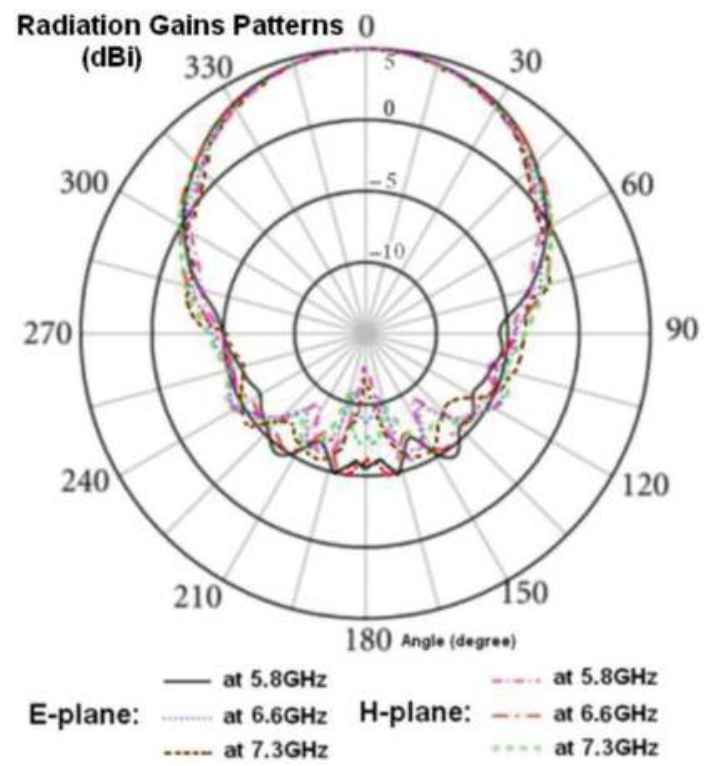

Figure 18. E- and H-plane radiation patterns at 5.8, 6.6, and $7.3 \mathrm{GHz}$.

\section{UWB antenna using T-shaped slit MTM unit cells}

In this section, a miniature and compact antenna design is described for integration in UWB wireless systems. The antenna exhibits good overall performance in terms of radiation patterns, gain, and efficiency. The proposed antennas are based on metamaterial unit cells that are implemented using T-shaped dielectric slits that were etched directly on the radiating patch, and include a spiral stub which is grounded using a via-hole. The T-shaped slit behaves as a left-handed series capacitance, and the grounded spiral acts as a left-handed shunt inductance. Results show just two unit cells were sufficient to realize the desired antenna performance.

The equivalent circuit model of the T-shaped slit antenna is based on the composite right-/ left-handed transmission-line structure shown in Figure 19. Standard printed circuit board manufacturing techniques were employed in the fabrication of the left-handed series 
capacitors $\left(C_{L}\right)$ and the left-handed shunt inductors $\left(L_{L}\right)$. The T-shaped dielectric slits and the spiral-shaped conductors were implemented on the radiation patch. The MTM unit-cell consists of two T-shaped dielectric slits etched on a rectangular patch with a conductive spiral located between the two slits. The spiral is grounded using a metallic via-hole. This technique substantially reduces the size of the UWB antenna because, unlike conventional antennas, its size is not dependent on the operating wavelength. The parasitic right-handed series inductance $\left(L_{R}\right)$ and shunt capacitance $\left(C_{R}\right)$ result from the current flowing over the antenna and the voltage gradient created between the microstrip and the ground-plane.

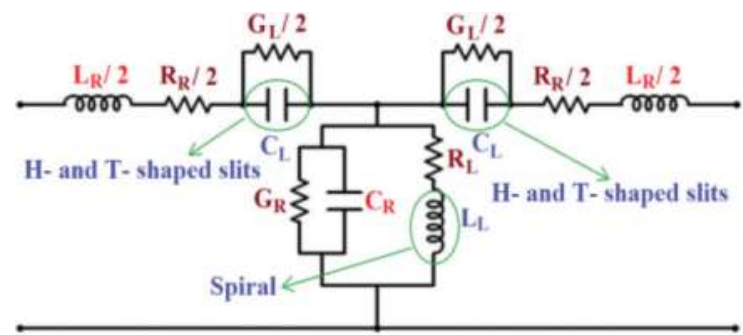

(a) Equivalent circuit model of the T-shaped slit MTM unit cell.

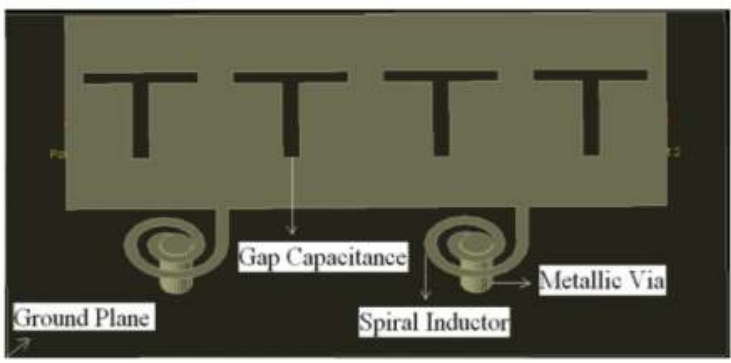

(b) Simulation model of the T-shaped slit antenna

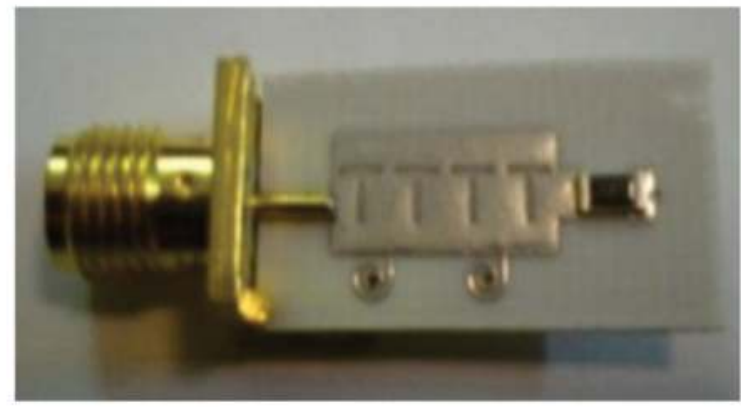

(c) Fabricated antenna prototype

Figure 19. (a) Equivalent circuit model of the T-shaped slit MTM unit cell (b) Simulation model of the T-shaped slit antenna (c) Fabricated antenna prototype. 
The proposed antenna was designed and fabricated on RT/duroid ${ }^{\circledR}$ RO4003 substrate with dielectric constant of 3.38 and $0.8 \mathrm{~mm}$ thickness. Figure 19(c) shows the configuration of the antenna, which is excited from left-hand side through a $50 \Omega$ microstrip feed-line. The righthand side of the patch is terminated with a matched load of $50 \Omega$ (SMD1206) that is connected to the ground-plane through a metallic via-hole. The total electrical length, width, and height of antenna are $0.05 \lambda_{0^{\prime}} 0.02 \lambda_{0^{\prime}}$ and $0.002 \lambda_{0^{\prime}}$ which correspond to $15.5 \mathrm{~mm}, 6.9 \mathrm{~mm}$, and $0.8 \mathrm{~mm}$, respectively. The optimized parameters of the antenna are given in Table 8, whose equivalent circuit parameters are $C_{L^{\prime}} L_{L^{\prime}} C_{R^{\prime}}$ and $L_{R}$ are $5 \mathrm{pF}, 6.4 \mathrm{nH}, 1 \mathrm{pF}$, and $2.8 \mathrm{nH}$, respectively.

\begin{tabular}{ll}
\hline Length of T slits & $3.0 \mathrm{~mm}$ \\
Width of T slits & $0.4 \mathrm{~mm}$ \\
Distance between slits & $0.4 \mathrm{~mm}$ \\
Width of spirals & $0.2 \mathrm{~mm}$ \\
Spacing of spirals & $0.2 \mathrm{~mm}$ \\
Turns of spirals & 2 \\
Height of via-hole & $0.8 \mathrm{~mm}$ \\
Length of $50 \Omega$ load (SMD1206) & $4.2 \mathrm{~mm}$
\end{tabular}

Table 8. T-shaped slit MTM antenna parameters.

The antenna resonates at three frequencies, i.e., 2, 3.7, and $5.8 \mathrm{GHz}$, as shown in Figure 20. The measured gain and efficiency of antenna have a maximum value of $7.1 \mathrm{dBi}$ and $91 \%$, respectively, at $3.7 \mathrm{GHz}$.

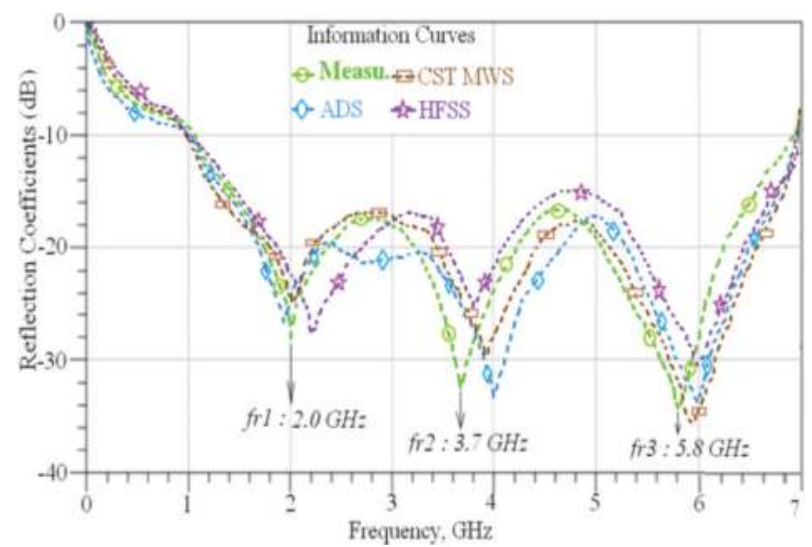

Figure 20. Simulated and measured reflection-coefficient response of the T-shaped slit antenna.

The measured radiation patterns at three spot frequencies in Figure $\mathbf{2 1}$ show the antenna radiates directionally. The measured gain and efficiency response of the antenna in Figure 22 show the antenna operates from 0 to $7 \mathrm{GHz}$ with a maximum gain and efficiency of $7.1 \mathrm{dBi}$ and $91 \%$, respectively, at $3.7 \mathrm{GHz}$. 


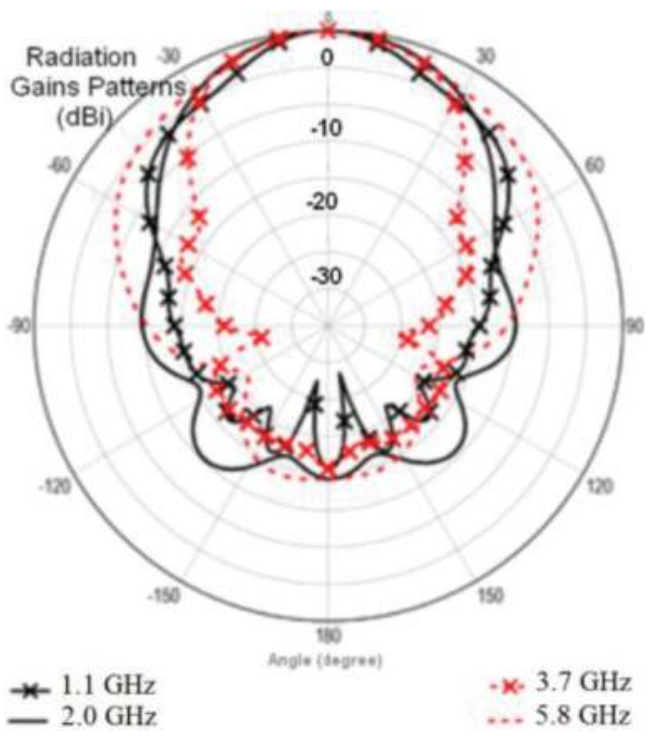

Figure 21. Measured radiation patterns of the T-shaped slit antenna.

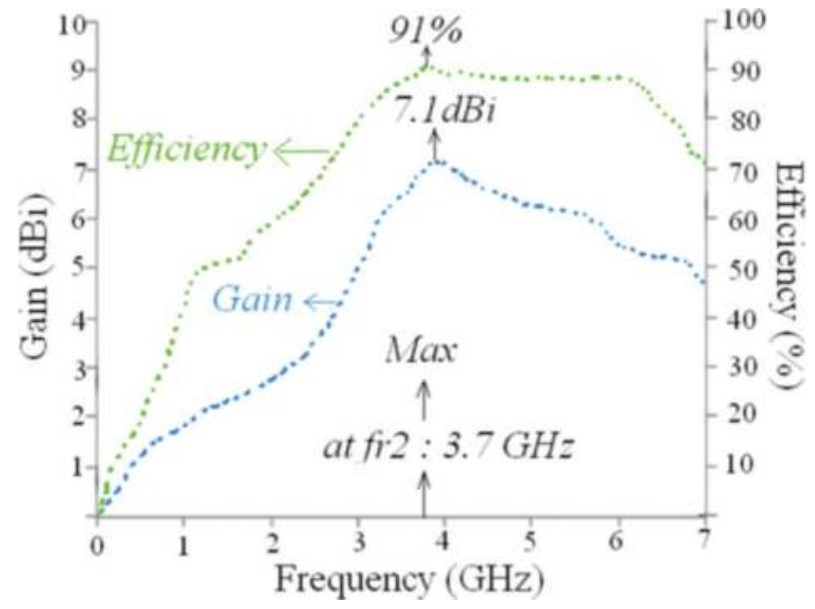

Figure 22. Measured gain and efficiency response of the T- shaped slit MTM antenna.

Comparison of the proposed antennas with other conventional antennas is given in Table 9 . It is evident the T-shaped antenna offers superior performance.

The effect of the slit dimensions on the antenna characteristics was investigated. It is evident from Figure 23 that increasing the length and width of slits improves the antenna's impedance bandwidth and matching performance. In fact, the bandwidth improves by $25 \%$ from 119 to $149 \%$ for increase in slit length from 1 to $3 \mathrm{~mm}$, and width from 0.2 to $0.4 \mathrm{~mm}$. 
The number of slits and spiral were also investigated. By increasing the number of slits in each unit-cell, the number of spirals had a positive impact on the antenna's bandwidth and matching properties, as shown in Figure 24. It is also observed that by increasing the number of slits causes the number of resonance frequencies to increase as well as its bandwidth. The gain and radiation efficiency of the antenna as a function of slit dimensions, the number of slits in the unit-cell, and number of spirals were also investigated. From Figures 25 and 26, it is evident that by increasing the length and width of the slits, and increasing the number of slits, the gain and radiation efficiency increase considerably. This is attributed to increase in the antenna aperture.

\begin{tabular}{|c|c|c|c|c|}
\hline Ref. & Dimensions & Fractional bandwidth & Max. gain & Max. eff. \\
\hline [27]- $a$ & $\begin{array}{l}0.04 \lambda_{0} \times 0.021 \lambda_{0} \times \\
0.002 \lambda_{0}\end{array}$ & $105 \%$ & $2.3 \mathrm{dBi}$ & $62 \%$ \\
\hline$[27]-b$ & $\begin{array}{l}0.05 \lambda_{0} \times 0.01 \lambda_{0} \times \\
0.002 \lambda_{0}\end{array}$ & $124 \%$ & $2.8 \mathrm{dBi}$ & $70 \%$ \\
\hline$[28]-a$ & $\begin{array}{l}0.45 \lambda_{0} \times 0.17 \lambda_{0} \times \\
0.02 \lambda_{0}\end{array}$ & $74 \%$ & $2.1 \mathrm{dBi}$ & $44 \%$ \\
\hline$[28]-b$ & $\begin{array}{l}0.42 \lambda_{0} \times 0.17 \lambda_{0} \times \\
0.041 \lambda_{0}\end{array}$ & $83 \%$ & $3.1 \mathrm{dBi}$ & $59 \%$ \\
\hline [19] & $\begin{array}{l}0.44 \lambda_{0} \times 0.22 \lambda_{0} \times \\
0.008 \lambda_{0}\end{array}$ & $18 \%$ & $2.2 \mathrm{dBi}$ & $17 \%$ \\
\hline [29] & $\begin{array}{l}0.24 \lambda_{0} \times 0.3 \lambda_{0} \times \\
0.009 \lambda_{0}\end{array}$ & $8 \%$ & $1.5 \mathrm{dBi}$ & $58 \%$ \\
\hline T-slit ant. & $\begin{array}{l}0.05 \lambda_{0} \times 0.02 \lambda_{0} \times \\
0.002 \lambda_{0}\end{array}$ & $144 \%$ & $7.1 \mathrm{dBi}$ & $91 \%$ \\
\hline
\end{tabular}

Table 9. Comparison of the proposed antennas.

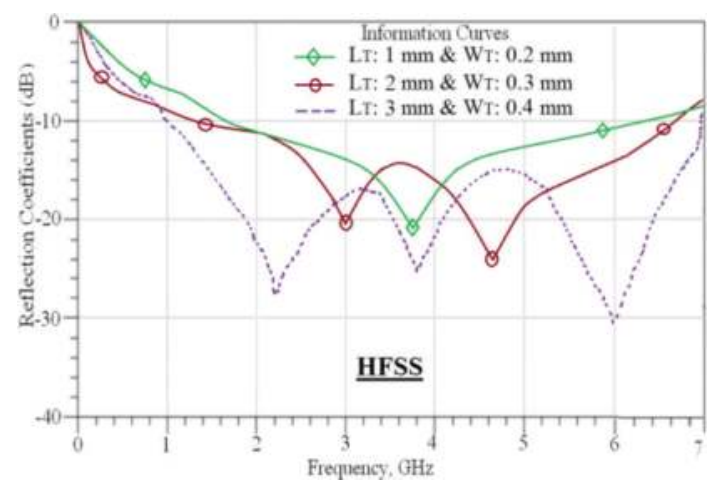

Figure 23. Effect of slit length and width on the antenna bandwidth. 


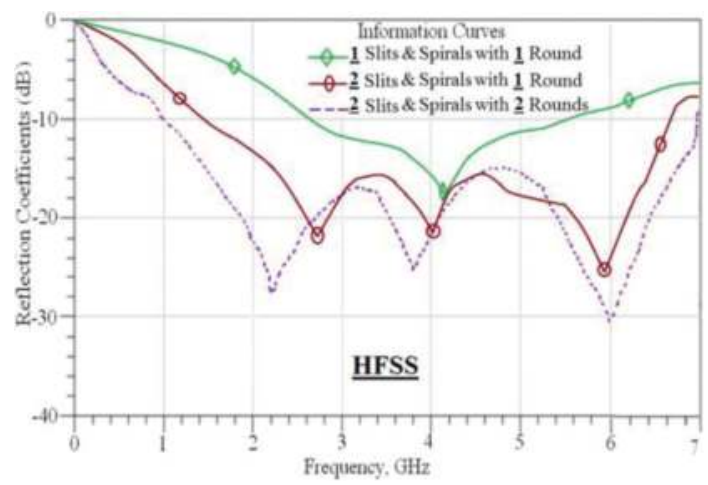

Figure 24. Impedance bandwidth as a function of number of slits in each of the unit cells and number of spirals.

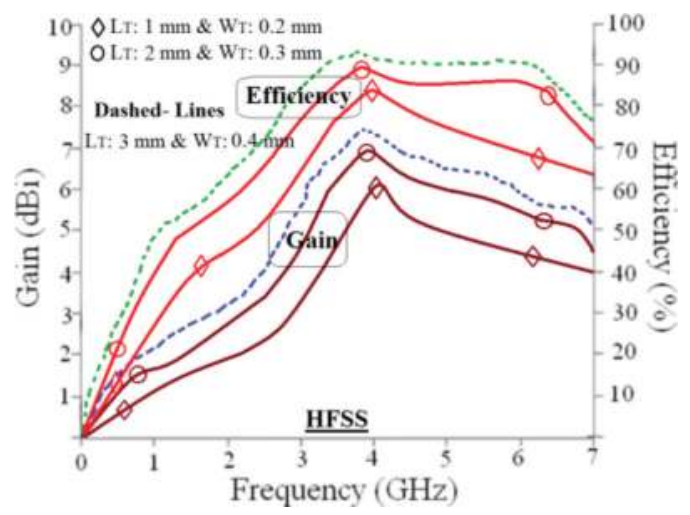

Figure 25. Gain and radiation efficiency as a function of slit dimensions.

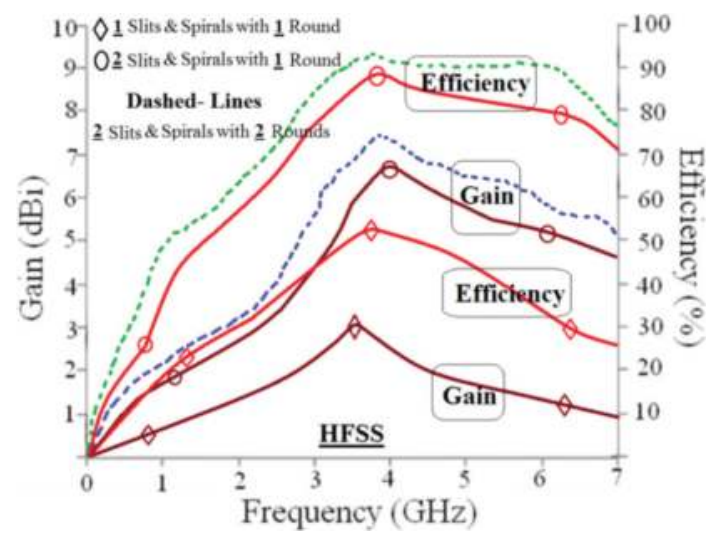

Figure 26. Gain and radiation efficiency as a function of number of slits and number of spirals. 


\section{Acknowledgements}

The authors would like to give their special thanks to faculty of microelectronics for the financial supports.

\section{Author details}

Mohammad Alibakhshikenari ${ }^{1 *}$, Mohammad Naser-Moghadasi², Ramazan Ali Sadeghzadeh Bal Singh Virdee ${ }^{4}$ and Ernesto Limiti ${ }^{1}$

*Address all correspondence to: Alibakhshikenari@ing.uniroma2.it

1 Department of Electronic Engineering, University of Rome Tor Vergata, Rome, Italy

2 Faculty of Engineering, Science and Research Branch, Islamic Azad University, Tehran, Iran

3 Faculty of Electrical Engineering, K. N. Toosi University of Technology, Tehran, Iran

4 London Metropolitan University, Center for Communications Technology, London, UK

\section{References}

[1] P. Gao, S. He, X. Wei, Z. Xu, N. Wang, and Y. Zheng, “Compact Printed UWB Diversity Slot Antenna with $5.5 \mathrm{GHz}$ Band-Notched Characteristics", IEEE Antennas Wireless Propag. Lett.," 2014; 13: 376-379. DOI: 10.1109/LAWP.2014.2305772

[2] A.A. Kalteh, G.R. Dadash-Zadeh, M. Naser-Moghadasi, and B.S. Virdee, "UltraWideband Circular Slot Antenna With Reconfigurable Notch Band Function," IET Microwave Antennas Propag., 2012; 6: 108-112.

[3] L. Li, Z.L. Zhou, J.S. Hong, and B.Z. Wang, "Compact Dual-Band Notched UWB Planar Monopole Antenna with Modified SRR," Electron Lett., 2011; 47: 950-951.

[4] M. Alibakhshi-Kenari, M. Naser-Moghadasi, and R.A. Sadeghzadah, "The Resonating MTM Based Miniaturized Antennas for Wide-Band RF-Microwave Systems," Microwave Opt. Technol. Lett., 2015; 57: 2339-2344.

[5] J. Long, and D.F. Sievenpiper, "A Compact Broadband Dual-Polarized Patch Antenna for Satellite Communication/Navigation Application," IEEE Antennas Wireless Propag. Lett., 2015; 14: 273-276.

[6] Nasimuddin, Y.S. Anjani, and A. Alphones, "A Wide-Beam Circularly Polarized Asymmetric-Microstrip Antenna," IEEE Trans. Antennas Propag., 2015; 62(12): 6506-6509.

[7] Nasimuddin, X.M. Qin, and Z.N. Chen, "A Compact Circularly Polarized Slotted Patch Antenna for GNSS Applications," IEEE Trans. Antennas Propag., 2015; 63(8): 3764-3768. 
[8] K. Agarwal, Nasimuddin, and A. Alphones, "Triple-Band Compact Circularly Polarised Stacked Microstrip Antenna Over Reactive Impedance Meta-Surface for GPS Applications," IET Microwaves Antennas Propag., 2014; 8(13): 1057-1065.

[9] C. Zhou, G. Wang, Y. Wang, B. Zong, and J. Ma, “CPW-Fed Dual-band Linearly and Circularly Polarized Antenna Employing Novel Composite Right/Left-Handed Transmission-Line," IEEE Antennas Wireless Propag. Lett. 2013; 12: 1073-1076.

[10] M. Alibakhshi-Kenari, M. Naser-Moghadasi, B.S. Virdee, A. Andujar, and J. Anguera, "Compact Antenna Based on a Composite Right/Left Handed Transmission Line," Microwave Opt. Technol. Lett., 2015; 57:1785-1788.

[11] M. Alibakhshi-Kenari and M. Naser-Moghadasi, "Novel UWB Miniaturized Integrated Antenna Based on CRLH Metamaterial Transmission Lines," AEU Int. J. Electron Commun., 2015; 69: 1143-1149.

[12] M. Alibakhshi-Kenari, M. Naser-Moghadasi, and R.A. Sadeghzadah, “On the Bandwidth and Radiation Specifications Enhancement of Monopole Antennas Loaded with Split Ring Resonators," IET Microwaves Antennas Propag., 2015; 9(14): 1487-1496. DOI: 10.1049/ iet-map.2015.0172

[13] R.W. Ziolkowski and A.D. Kipple, "Application of Double Negative Materials to Increase the Power Radiated by Electrically Small Antennas," IEEE Trans. Antennas Propag., 2003; 51(10): 2626-2640.

[14] G.V. Eleftheriades, A. Grbic, and M. Antoniades, "Negative-Refractive-Index Transmission-Line Metamaterials and Enabling Electromagnetic Applications," Proc. IEEE Antennas Propag. Int. Symp., 2004: 1399-1402.

[15] R.W.Ziolkowski, P. Jin, and C.-C. Lin, "Metamaterial-Inspired Engineering of Antennas," Proc. IEEE, 2011; 99(10): 1720-1731.

[16] M. Alibakhshi-Kenari, “Design and Modeling of New UWB Metamaterial Planar Cavity Antennas with Shrinking of the Physical Size for Modern Transceivers," Int. J. Antennas Propag., 2013; Article ID 562538: 12p. DOI: 10.1155/2013/562538

[17] Mohammad Alibakhshi-Kenari, Masoud Movahhedi and Hadi Naderian, "A New Miniature Ultra Wide Band Planar Microstrip Antenna Based on the Metamaterial Transmission Line" 2012 IEEE Asia- Pacific Conference on Applied Electromagnetics (APACE 2012), December 11-13, 2012, Melaka, Malaysia.

[18] M. Alibakhshi-kenari and M. Naser-Moghadasi, "Novel CRLH-CP Antenna with the Capability to be Integrated Inside RF Components for RF Electronic Devices and Embedded Systems," J. Appl. Comput. Electromagn. Soc., 2015; 30(6): 653-659.

[19] C.J. Lee, M. Achour, and A. Gummalla, "Compact Metamaterial High Isolation MIMO Antenna Subsystem," Microwave Conference, 2008. APMC 2008. Asia-Pacific, 6-20 Dec. 2008, pp, 1-4. 
[20] C.J. Lee, K.M.K.H. Leong, and T. Itoh, "Broadband Small Antenna for Portable Wireless Application," International Workshop on Antenna Technology: Small Antennas and Novel Metamaterials, 2008: 10-13.

[21] A. Lai, C. Caloz, and T. Itoh, "Composite Right/Left-Handed Transmission Line Metamaterials," IEEE Microwave Mag., 2004; 5(4): 34-50.

[22] C.-J. Lee, K.M.K.H. Leong, and T. Itoh, "Composite Right/Left-Hand-Handed Transmission Line Based Compact Resonant Antennas for RF Module Integration," IEEE Trans. Antennas Propagat., 2006; 54(8): 2283-2291.

[23] C. Caloz and T. Itoh, "Application of the Transmission Line Theory of Left-Handed (LH) Materials to the Realization of a Microstrip "LH Line"," Proc. IEEE Antennas Propag. Soc. Int. Symp., 2002; 2: 412-415.

[24] Christophe Caloz and Tatsuo Itoh, "Electromagnetic Metamaterials: Transmission Line Theory and Microwave Applications", ISBN: 978-0-471-66985-2, 376 pages, December 2005, Wiley-IEEE Press.

[25] A. Sanada, C. Caloz, and T. Itoh, "Planar Distributed Structure with Negative Refractive Index," IEEE Trans. Microwave Theory Tech., 2004; 52(4): 1252-1263.

[26] C. Caloz, T. Itoh, and A. Rennings, "CRLH Traveling-Wave and Resonant Metamaterial Antennas," Antennas Propagat. Mag., 2008; 50(5): 25-39.

[27] Mohammad Alibakhshi-Kenari, "Printed planar patch antennas based on metamaterial", International Journal of Electronics Letters, Volume 2, Issue 1, Jan 2014, pp 37-42.

[28] M. Alibakhshi-Kenari, "Introducing the New Wide Band Small Plate Antennas with Engraved Voids to Form New Geometries Based on CRLH MTM-TLs for Wireless Applications," Int. J. Microwave Wireless Tech., 2014; 6(06): 629-637. DOI: http://dx.doi. $\operatorname{org} / 10.1017 / S 1$

[29] C.-C. Yu, M.-H. Huang, L.-K. Lin, Y.-T. Chang, "A Compact Antenna Based on Metamaterial for WiMAX," Asia-Pacific Microwave Conference, 16-20 Dec. 2008, pp, 1-4. 
